\title{
Plant-Based Vaccine for Livestock: Key Points to Unleash Platform Translation in Developing Countries
}

\author{
María Sol Pérez Aguirreburualde $^{1} \cdot$ Silvana Petruccelli $^{2} \cdot$ Fernando Bravo Almonacid $^{3}$. \\ Andrés Wigdorovitz ${ }^{4}$
}

Published online: 17 October 2016

(C) Springer International Publishing AG 2016

\begin{abstract}
Purpose of review Ten years ago the first plant-based vaccine was licensed (DowAgrosciences). It was only 20 years after the first report of a recombinant protein obtained through plant transformation technology. Back then, this vaccine was perceived as the first of an unlimited list of innovative products of a flourishing platform. Unexpectedly, since then, no other veterinary product based on plant molecular pharming (PMP) has reached the market. This review will reflect a transdisciplinary view of the status and challenges that the
\end{abstract}

This article is part of the Topical Collection on Enhancing Agricultural Production

María Sol Pérez Aguirreburualde

perezaguirreburualde.m@inta.gob.ar; solperezburu@gmail.com

Silvana Petruccelli

silvana@biol.unlp.edu.ar

Fernando Bravo Almonacid

fbravo@dna.uba.ar

Andrés Wigdorovitz

wigdorovitz.andres@inta.gob.ar

1 Instituto de Patobiología, CICVyA, INTA, Dr. Nicolás Repetto y De Los Reseros s/ ${ }^{\circ}$, B1681FUU Hurlingham, Buenos Aires, Argentina

2 CIDCA, Facultad de Ciencias Exactas, UNLP, CCT-La Plata CONICET, Calle 116 y 47, B1900AJJ La Plata, Argentina

3 Laboratorio de Virología y Biotecnología Vegetal, INGEBI-CONICET, Vuelta de Obligado 2490, C1428ADN Ciudad Autónoma de Buenos Aires, Argentina

4 INCUINTA, CICVyA, INTA and Consejo Nacional de Investigaciones Científicas y Técnicas (CONICET), Dr. Nicolás Repetto y De Los Reseros s/ $\mathrm{N}^{\circ}$, B1681FUU Hurlingham, Buenos Aires, Argentina molecular farming platform faces to become a strategic solution for the agroindustrial sector of developing countries.

Recent findings Plant-based veterinary vaccines (PBVV) have the potential to give answers to several challenges that animal health presents today. The urgent need to improve livestock productivity, especially in low and middle-income countries (LMIC), and the current concern about the emergence of antimicrobial resistance associated with animal production, demands new products such as inexpensive vaccines and therapeutics. Based on the translational research scheme, certain barriers that could have limited the development into products of many results obtained in the last 15 years were identified.

Summary Unquestionably, the development of innovation in LMIC is a key element in the feasibility of the platform. The emergence of PPP between multiple stakeholders as a strategy to overcome the existing disconnection between academia and industry, could enable the conversion of leading vaccine candidates from the stage of proof of concept into prototypes for industry, and thereby foster 'productization' in the field of veterinary vaccines.

Keywords Innovation · Livestock · Molecular farming · Plant-based vaccines $\cdot$ Translational research

\section{Introduction}

The livestock sector worldwide is facing great challenges. There are more than 1 billion head of cattle in the world. The main livestock producers worldwide are India, Brazil, and China, with populations ranging from 100 to approximately 300 million heads; followed by the United States, European Union and Argentina [1]. Drivers such as population growth, urbanization, and most importantly, increasing 
income have resulted in a rapid rise in demand for livestock products in LMIC. On the contrary in developed countries, the demand is stagnating, heavily moderated by socio-cultural factors related to human health concerns and environmental sustainability $[2,3]$.

In LMIC, livestock contributes more than $33 \%$ to agricultural GDP (gross domestic product), and is one of the fastest growing agricultural sub-sectors [4]. Its importance as a major contributor to food and nutritional security, and as a livelihood source for nearly 1 billion inhabitants, prevents one to underestimate its role in attaining the Millennium Developing Goals (MDG) [5].

In order to cope with the rapidly increasingly demand the livestock sector needs to adapt fast. The lack of available new land prohibits a 'horizontal' expansion of existing modes of production, and forces the sector into rapid technological changes to increase resource efficiency and higher output per animal [3]. Innovation in animal health, through biotechnological applications, has been widely report to have a greater potential to achieve such increase in productive efficiency than other technologies [6]. Within those, vaccines have proven to be one on the most cost-effective strategies to be pursued [7].

After the molecular biology breakthrough in the late 1970s, the concept of subunit vaccine arose as a safe and highly characterized option that would target immune response toward specific epitopes. Since then huge advances have been made which were translated into products for human and veterinary health $[7,8]$. In 1986, the first recombinant protein obtained through plant transformation technology was reported [9]. After that the use of transgenic plants for the production of antigens was repeatedly described as a biotechnological strategy with several advantages in comparison to other conventional production systems [10,11]. Particularly, for those niches with scares resources, like veterinary industry or neglected diseases in developing countries [12•,13,14].

Ten years ago the first plant-based veterinary vaccine (PBVV) was licensed (Dow Agrosciences). Back then, this vaccine was perceived as the first of an unlimited list of innovative products of a flourishing platform. Unexpectedly, since then no other veterinary product based on molecular farming has reached the market. Without entailing that a significant decrease in basic research carried out in the discipline.

Recently, several reviews were published covering the analysis of a wide spectrum of different factors that could be involved in this delay in translation into products based in PMP [15-17]. Based on these reports, the analysis of the PMP timeline shows that the focus of concern shifted through the years, proving the evolution of the platform. Initially the focus was mainly on technical production issues, for later implementation and adoption challenges gained prominence. While, many of the technical difficulties marked once as limitations, such as: length of time of upstream development, low recombinant protein yields or weak immunogenicity related to subunit vaccines, have been solved with different strategies [8, 12•], new challenges have arisen. Those associated mainly with downstream economic feasibility, regulatory issues, and social perceptions [18• $19,20 \bullet 21]$.

From the beginning, the interest in PMP has been related with the potential low cost, safety, and easy scalability focusing on therapeutic and preventive antibody-based products and vaccines $[22 \bullet \bullet, 23,24]$. Potential of PMP has been demonstrated with the approval of the first made biologic: glucocerebrosidase in 2012 produced in carrot cell culture [25], the recently commercial launch of tobacco made human collagen for wound treatments in Italy (www.collplant.com), and several human vaccines, antibodies, and other biologics in clinical trials [17]. Although veterinary vaccines were a relevant target of PMP several constrains made them less appealing for big-pharma sector and governmental authorities, therefore limited resources were invested. Nevertheless, PMP are now mature to brace the challenge of bringing PBVV to the market. Furthermore, adoption of an innovative platform, as plant-based vaccines, in LMIC present some particular features that may require a deeper analysis to identify, efficiently, the key points that would need to be overcome to make the translation of this platform feasible.

The aim of the review is to present a trans-disciplinary view of the status and challenges that the molecular farming platform faces to become a strategic solution for the agroindustrial sector of developing countries.

\section{From Bench to Farm}

Translational research (TR) has appeared recently as a highly interdisciplinary field, the primary goal of which is to coalesce assets of various natures within the individual pillars in order to "translate" findings in fundamental research into practice and meaningful health outcomes [26]. Veterinary translational research as any other subfield of TR, requires an approach that considers the particular set of rules that govern livestock health sector decision makers [27, 28]. Briefly, TR is broken down into a different number of stages schemes. On the basis of 2-stage-scheme, T1: represents the translation of basic research results into efficacy products, while, T2: represents the implementation of those potential into the target population. And then, a third stage (T3) that can be distinguished as the feed-back from the outcomes already implemented into the population, as the new "scenario", plausible of improvement through new research (Fig. 1).

\section{T1: Technical Feasibility}

Since the first developments in plant-based protein production, safety, efficient post-transcriptional modification, scale 
Fig. 1 Translational research scheme for PBVV. T1-T2-T3: critical translational stages from basic discoveries to population health impact. PMP Plant molecular pharming, $P B V V$ Plant based veterinary vaccines, $P P P$ Public-private partnership, GLP/ GMP Good laboratory/ manufacturing practices, $Q b D$ Quality by design

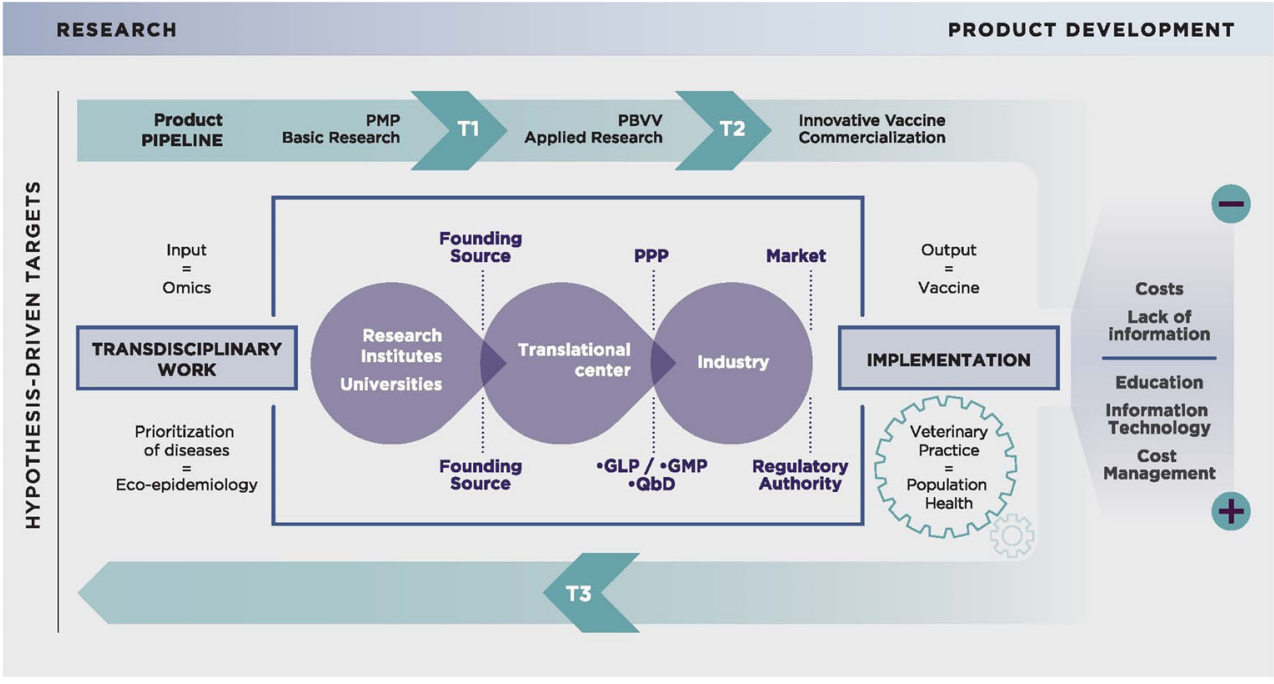

up simplicity, and low cost associated, have been described as the main advantages of this system in comparison to other expression platforms. On one hand the variety of plant species and transformation protocols evaluated in the last decades allowed the generation of a deep understanding of the complexity of plant expression mechanisms. On the other hand, the widespread efforts could have led to the accomplishment of a robust and mature platform that could have engaged the biotech industry sooner. This situation has been partially tackled by the effort to consolidate the available knowledge in a few technologies, leading to consolidated pipelines for industrial production, each of those with specific advantages and disadvantages $[16,17]$. Recent advances achieved on expression strategies, product yields, and process development have already been reviewed [29], and an updated comparison of available expression technologies bolster the platform strength [19]. Here we highlight the key strategies that seem to have greater forecast for veterinary biological products in LMIC.

The development of hybrid vectors that combine the advantages of gene transfer from Agrobacterium and the ability of virus replicative RNA amplification allowed increased yields ( $\mathrm{g} / \mathrm{kg}$ of biomass). There is currently a wide range of vectors available, systems employing both, temporary or stable expression [30]. Currently, plastid transformation and agroinfiltration technologies are seen as two more versatile and time-saving options [31]. Although, many proteins expressed in chloroplast associate with high yields (up to $70 \%$ of total soluble protein), it lacks the capacity to glycosylate proteins which makes it only suitable for a subset of protein targets $[32,33]$.

Upstream costs of this platform are significantly advantageous compared to others [12•]. Even though, many reports agree that these are not enough to deliver economic feasibility to the entire process, as in downstream phase resides up to $80 \%$ of the total cost $[18 \cdot]$. To overcome this, alternative low cost methodologies have been developed to complete the platform, such as oleosins [34], hydrophobins [35], ZERA (gamma zein derived sequence) [36], and elastin like polymers (ELP) [37] technologies. Using these fusion-tags chromatographic column steps are replaced by simple and amenable to industrial-scale methods such as aqueous two-phase separation or cycles of phase transition and centrifugation [18•, 38]. Moreover, fusion to ELP enhances the expression of the recombinant proteins and improves antigen efficacy [37, 39-41], fusions to ZERA also provide a method to increase antigen half-life in blood increasing its efficacy at low doses (www.zipsolutions.es) [42, 43]. Oleosin oil bodies also work as vaccine delivery systems [44]. Plant produced vaccines could also be administered orally since encapsulation within plant cell provides some protection reducing degradation in the gastrointestinal tract $[45,46]$. Plants have mucoadhesive compounds that enhance intestinal uptake and secondary metabolites could act as adjuvants [47]. Several vaccines intended for oral administration are currently in different phases of clinical evaluation such as against enterotoxigenic E. coli, Vibrio cholerae, Norovirus, hepatitis B virus, rabies virus produced in different plant species such as potatoes, corn, lettuce, spinach or rice [17].

Another limitation described for subunit vaccines is that recombinant antigens are often poorly immunogenic [7]. To increase antigen immune stimulatory activity several successful and promising approaches have been used such as in plant production of virus-like particles (VLPs) [48], targeting of antigen to antigen presenting cells (APC) [49], fusion to mucosal adjuvants such as cholera toxin B subunits or $E$. coli heat labile enterotoxin B $[50,51]$ or Lumazine synthase from Brucella spp. (BLS) [52, 53], and recently to the Toll-like receptor (TLR) 5 agonist bacterial flagellin [54] a potent systemic and mucosal adjuvant. Medicago Inc's VLP technology applied to the pandemic flu vaccine has completed human clinical phase II and has obtained an emergency use 
authorization, while the quadrivalent seasonal influenza vaccines is currently in phase II [55]. One advantage of developing vaccines for veterinary health compared to human is that the use of adjuvants is currently less restricted [56] given the opportunity to develop novel vaccine formulations.

Another particular feature that was described as an advantage of veterinary vaccines is that regulatory requirements are less exigent than for human use [57]. This is the reason why many research groups have already targeted the use of molecular farming in this area.

\section{T2: Technology Transference—Vaccine Implementation}

By 2000 there was a lack of regulatory framework for plantbased pharmaceuticals. Then, the first plant-based products to reach the market were those that did not require clinical trials, as enzymes or reagents [58]. The key importance of these products was to demonstrate that molecular farming can be economically viable [51]. Since then, intensive work has been done to create solid regulatory recommendation with concern to products manufacturing, safety determination, containment, and reduction of environmental risk [59]. A recent report based on a workshop sponsored by the Organization for Economic Co-operation and Development (OECD) [20•], provided of a guideline for developing business plans for PBVV, making an excellent work reviewing in a comparative and attainable way the regulatory framework for PBVV in different countries. Although the level of strictness of those regulations on transgenic plants may vary, in general, all of them have the general goal to address safety concerns for the public health (direct and indirect risk) and for the environment [60]. In this scenario, PBVV seem to have greater potential of production in containment, not only because of the shorter regulatory path required, but also, as it has been proven that the greater productivity achieved in control environmental conditions, like greenhouses, outstrips the advantages of field production [61]. Nowadays, the costs of building a GMP compliant facility for growing plants are much lower than for a cell fermentation facility of equivalent production capacity [22••]. Already, nine GMP-compliant plant factories for biopharmaceuticals exist in the world [17], nevertheless none of them are in LMIC countries.

Even though, as technological advances will continuously keep appearing, new challenges in concern to regulatory framework will breeze in.

\section{Market Dynamic}

Global market of veterinary vaccines (GVVM) is in its growth phase. Estimations predict it would grow at a rate between 5.5 and $8.1 \%$ CAGR (CAGR=compound annual growth rate) and reach US $\$ 14,000 \mathrm{Mn}$ by 2026 . The livestock animals segment is expected to witness relatively impressive growth during the forecast period mainly in LMIC [62].

Even though, local pharmaceutical companies seem reluctant to invest in innovative technology without evidence of utility. This fact could be, at least partially, due to another hurdle to overcome by PBVV which is the asymmetry in regulatory issues for approval of veterinary biological between countries. Experiences from LMIC clearly show that it is not sufficient to rely on voluntary adherence to the minimum requirements of the World Organization for Animal Health (OIE) or pharmacopoeia [63]. Independent and secondary-level quality control testing employing test procedures which have been standardized in the region by an independent (preferably regional) institution are prerequisites for minimizing the risk of poor-quality or potentially unsafe vaccines being widely used [64]. This could mean that in certain contexts the lack of update effectiveness requirements would threaten the ability of enhanced vaccines to prove superiority compared to traditional products, hampering its competitiveness on the market [65•].

The introduction of any technological innovation into a conservative industry is not a simple task. The traditional veterinary vaccine industry is not an exception for that, particularly, as it works generally with a narrower margin than the human pharmaceutical industry [66]. The veterinary vaccine market (VVM) is based on a very intuitive principle: while livestock diseases can have both direct and indirect costs [67], any intervention design to control those diseases, must be cost effective [68]. This means that to prove the feasibility of a new vaccine is not enough to demonstrate its immunogenicity, but also to generate enough complementary evidence of its cost effectiveness [69]. A recent report, that analyzed the validity of studies that assess the effectiveness of interventions (EoI) concluded that, currently the internal and external validity of veterinary EoI studies is limited compared to human ones [65•]. This fact can significantly jeopardize the chances of commercialization of a new vaccine based on the uncertainty that often exists about the major benefits associated with its adoption [70]. In economics, information failure is described as an asymmetry in the information between the participants in an economic exchange, leading in most of the cases to a misallocation of scarce resources, which results in an unbalance of demand and supply in the market [71]. If the key stakeholders involved in VVM do not receive the right information about effectiveness of the new generation of vaccines, the proper evidence-based demand for those products is not likely to exist, and consequently, the industry will not have the stimulus to adopt that kind of innovation. This scenario would be even more significant, in many LMIC where still a scarcity of update regulation in concern to biological products for veterinary use exists [72]. An example of 
efforts to improve this situation, are the American Committee of Veterinary Medicinal Products (CAMEVET), which is a regional project with the aims to facilitate the harmonization of standards, records, and control of veterinary medicines among member countries, or the OIE PVS Pathway, which is a global program for the sustainable improvement of a country's Veterinary Services' compliance with OIE standards.

As reported in many LMIC a clear uneven situation of regulation between biological against infectious agents is included in OIE list A and others which can have a dramatic impact on livestock productive performance [73]. Notwithstanding there is limited research investigating the motivators and barriers to vaccinating livestock. While no compulsory vaccination strategy is applied, the decision of vaccination lies with the farmer [74].

Moreover, a not-for-profit organization named GALVMed, created Vetvac (http://www.vetvac.org) a global database of commercially available livestock vaccines. In a similar way, VIOLIN (Vaccine Investigation and Online Information Network) (http://www.violinet.org) exists as a resource of research data of commercial and clinical trials vaccines designed by the University of Michigan [56]. Interestingly, an analysis of these databases shows that most veterinary vaccines are killed or inactive infectious agents with very few examples of subunit vaccines, therefore there is a need to develop safe and effective, easy to deliver, and economically feasible livestock vaccines. This should be seen as an opportunity by the research community and innovative entrepreneurs of these countries, who should collaborate to overcome this issue through synergic efforts to produce and communicate compelling efficacy results, creating the right market for innovative tools. Moreover, enhancing markets for new vaccines could create a virtuous cycle of incentives for vaccine research funding [75].

\section{Biotech Sector in Developing Countries/Innovation in MLIC}

Industry generally prefers tried and tested delivery platforms for new vaccines as these can be more easily aligned with established manufacturing capabilities and a commercial target product profile (TPP). This alignment leaves little room for innovative but yet not validated vaccine technologies, to enter the product development path. Even though, there is a clear tendency of different stakeholders related to molecular farming to conceive strategies to overcome this challenge.

In the past two decades, there has been an important change in the global economic and scientific landscape.
Already in 2006, Korenblit described the concept of "Innovative developing countries" (IDC) [76]. A S7significant number of biotechnological breakthroughs are coming from developing countries like China and India, which are seeking a competitive edge in the world market. While many other IDC are making substantially investment in biotech research infrastructures (FMI, stats). The goal of build-up local scientific and technical expertise is a common feature to all of them [77]. On one hand, several national funding agencies in LMIC are making significant efforts to generate prioritization guidelines promoting knowledge translation, through encouraging exchange between researchers and private sector and decision-makers [78, 79]. On the other hand, there is a need for creative approaches, "innovative capacity" [80], to increase resources to consolidate regional scientific talent [81].

For example, the Brazilian biotech sector has made considerable progress in recent years toward becoming truly innovative. This sector comprises private enterprises as well as government-controlled institutes [82], involving the molecular farming consortium. In 2011, BioManguinhos/Fiocruz (www.bio.fiocruz.br) signed a collaboration agreement with iBio, Inc. and Fraunhofer USA Center for Molecular Biotechnology, to produce certain vaccines based upon iBio's proprietary technology. A recombinant yellow fever vaccine using VLP technology by transient expression system in $N$. benthamiana that has already been proved in animal model would be the first product. Further in 2013, BioManguinhos entered into a supply and technology transfer agreement with Protalix intended to transfer the capacity and skills required for the Brazilian government to construct its own manufacturing facility to produce glucocerebrosidase using carrot cell culture. These two cases show the strategic national plan that seeks to promote the interaction between private and public sector [83, 84]. Another sign of innovation in the region it is the recent approbation by SENASA (Argentina) of the first series of VEDEVAX, a subunit vaccine based on insect cells against BVDV [85]. Finally, two examples of public private partnership (PPP) like the Bharat Biotech center in India, which focuses on bringing solutions to public health of developing nations using novel technologies through strong collaborative research (www.bharatbiotech.com), that just recently, launched a live attenuated oral rotavirus vaccine and plans to make the vaccine available for US\$1.00 per dose for public markets; and, the ILVAC in Kenya [86] as a key milestone of PPP in animal health, with the aim to develop vaccine-based solutions that reduce disease burdens on livestock in developing countries; demonstrate the innovation development in LMIC is being materialized. 


\section{Conclusions}

The impact of vaccines in livestock populations cannot be overstated. Still veterinary vaccinology needs to deal with a wide spectrum of challenges. These include the development of cost effective strategies to prevent and control infectious diseases, taking into account animal welfare and focusing on decreasing production costs of animals used for food [87]. The presence of several PBV in clinical trials phase II and III, emphasizes that plant-produced targets have accomplished successfully the progression along the regulatory path $[15$, 88]. Also, tremendous results in understanding the immunological mechanisms to increase the right type of immune response have been done in the last few years, and can be incorporated to vaccine rational design. Indeed, quality by design $(\mathrm{QbD})$ framework would facilitate the continuous incorporation of cutting edge technology generated by other disciplines to the vaccine pipeline [89]. As we discussed earlier the reasonably high level of expertise in recombinant plant development in many centers in LMIC, make PMP a technology that is very well suited to be applied in PBVV in those countries [90].

The mentioned examples of collaborations highlight that it seems to be the right momentum for the emergence of PPP between multiple stakeholders as a strategy to overcome the existing disconnection between academia and industry in LMIC. The goal of these types of consortiums is to enable conversion of leading vaccine candidates from the stage of proof of concept into prototypes for industry, and thereby foster 'productization' in the field of Veterinary Vaccines and Diagnostics.

The Developing Countries Vaccine Manufacturers Network (DCVMN) is a unique model of a public and private international alliance $[91,92]$ that has achieved a significant and continuous growth over the last 15 years, counting today 45 members from 16 countries, not including any multinational company or subsidiary. Although, its first aim is to provide a consistent and sustainable supply of quality vaccines at an affordable price to developing countries, its members are also striving to accelerate the production of innovative vaccines, conceiving technology transfer and co-development as one of the most effective ways to do it [91]. Successful examples, like Meningococcal A vaccine co-development with PATHWHO and many others, demonstrated that these kinds of PPP models are essential to foster innovation in LMIC. Clearly, variables such as political will, long-term support, and policy coherence would be essential factors to conceive the sustainable appropriation of this innovative platform by local industry through the development of innovative capacity.

All above must be seen as inspiring elements to conceive similar networks between stakeholders in the veterinary vaccine sector in the next decades, which are described as a challenging but also as an extremely promising scenario for livestock production. PMP entrepreneurs should dive into these strategies to create synergies to fill the right niches of innovative products in veterinary health.

\section{Compliance with Ethical Standards}

Conflict of Interest Andrés Wigdorovitz, Fernando Bravo Almonacid, María Sol Pérez Aguirreburualde and Silvana Petruccelli declare that they have no conflicts of interest.

Human and Animal Rights and Informed Consent This article does not contain any studies with human or animal subjects performed by any of the authors.

\section{References}

Papers of particular interest, published recently, have been highlighted as:

- Of importance

•• Of major importance

1. FAO. FAOSTAT. 2015. http://faostat3.fao.org.

2. Thornton PK. Livestock production: recent trends, future prospects. Philos Trans R Soc Lond B Biol Sci. 2010;365(1554):2853-67. doi:10.1098/rstb.2010.0134.

3. Steinfeld H, Wassenaar T, Jutzi S. Livestock production systems in developing countries: status, drivers, trends. Rev Sci Tech. 2006;25(2):505-16.

4. Swanepoel F, Stroebel A, Moyo S. The role of livestock in developing communities: enhacing multifunctionality South Africa: The Technical Centre for Agricultural and Rural Cooperation (CTA); 2010.

5. UN. The Millennium Goals Report. New York, USA: United Nations2013 June 2013. Report No.: 978-92-1-101284-2.

6. Onteru S, Ampaire A, Rothschild M. Biotechnology developments in the livestock sector in developing countries. Biotechnol Genet Eng Rev. 2010;27:217-28.

7. Plotkin S. History of vaccination. Proc Natl Acad Sci U S A. 2014;111(34):12283-7. doi:10.1073/pnas.1400472111.

8. Moyle PM, Toth I. Modern subunit vaccines: development, components, and research opportunities. ChemMedChem. 2013;8(3): 360-76. doi:10.1002/cmdc.201200487.

9. Barta A, Sommergruber K, Thompson D, Hartmuth K, Matzke MA, Matzke AJ. The expression of a nopaline synthase-human growth hormone chimaeric gene in transformed tobacco and sunflower callus tissue. Plant Mol Biol. 1986;6(5):347-57. doi:10.1007/BF00034942.

10. Daniell H, Singh ND, Mason H, Streatfield SJ. Plant-made vaccine antigens and biopharmaceuticals. Trends Plant Sci. 2009;14(12): 669-79. doi:10.1016/j.tplants.2009.09.009.

11. Rybicki EP. Plant-based vaccines against viruses. Virol J. 2014;11: 205. doi:10.1186/s12985-014-0205-0.

12. Spiegel H, Boes A, Voepel N, Beiss V, Edgue G, Rademacher T, et al. Application of a scalable plant transient gene expression platform for malaria vaccine development. Front Plant Sci. 2015;6: 1169. doi:10.3389/fpls.2015.01169. This study demonstrates the use of a plant transient expression platform as essential component of a malaria vaccine development workflow. 
13. Rybicki EP, Chikwamba R, Koch M, Rhodes JI, Groenewald JH. Plant-made therapeutics: an emerging platform in South Africa. Biotechnol Adv. 2012;30(2):449-59. doi:10.1016/j. biotechadv.2011.07.014

14. Rybicki EP. Plant-made vaccines for humans and animals. Plant Biotechnol J. 2010;8(5):620-37. doi:10.1111/j.14677652.2010.00507.x.

15. Daniell H, Streatfield SJ, Rybicki EP. Advances in molecular farming: key technologies, scaled up production and lead targets. Plant Biotechnol J. 2015;13(8):1011-2. doi:10.1111/pbi.12478.

16. Sack M, Hofbauer A, Fischer R, Stoger E. The increasing value of plant-made proteins. Curr Opin Biotechnol. 2015;32:163-70. doi:10.1016/j.copbio.2014.12.008.

17. Takeyama N, Kiyono H, Yuki Y. Plant-based vaccines for animals and humans: recent advances in technology and clinical trials. Ther Adv Vaccin. 2015;3(5-6):139-54. doi:10.1177 /2051013615613272.

18. Lojewska E, Kowalczyk T, Olejniczak S, Sakowicz T. Extraction and purification methods in downstream processing of plant-based recombinant proteins. Protein Expr Purif. 2016;120:110-7. doi:10.1016/j.pep.2015.12.018. This study presents a summary of the information regarding the downstream processing in plant systems and provides a comprehensible overview of its key steps.

19. Topp E, Irwin R, McAllister T, Lessard M, Joensuu JJ, Kolotilin I, et al. The case for plant-made veterinary immunotherapeutics. Biotechnol Adv. 2016;34(5):597-604. doi:10.1016/j. biotechadv.2016.02.007.

20. MacDonald J, Doshi K, Dussault M, Hall JC, Holbrook L, Jones G, et al. Bringing plant-based veterinary vaccines to market: managing regulatory and commercial hurdles. Biotechnol Adv. 2015;33(8): 1572-81. doi:10.1016/j.biotechadv.2015.07.007. This works provides guidance in planning for the commercialization of plant-made vaccines for animal use. Particularly, in concern to regulatory framework.

21. Kolotilin I, Topp E, Cox E, Devriendt B, Conrad U, Joensuu J, et al. Plant-based solutions for veterinary immunotherapeutics and prophylactics. Vet Res. 2014;45:117. doi:10.1186/s13567-014-0117-4.

22.• Holtz BR, Berquist BR, Bennett LD, Kommineni VJ, Munigunti RK, White EL, et al. Commercial-scale biotherapeutics manufacturing facility for plant-made pharmaceuticals. Plant Biotechnol J. 2015;13(8):1180-90. doi:10.1111/pbi.12469. This study shows an integrated approach that demonstrated rapid, high-quality production of target molecules under GMP conditions.

23. Ma JK, Christou P, Chikwamba R, Haydon H, Paul M, Ferrer MP, et al. Realising the value of plant molecular pharming to benefit the poor in developing countries and emerging economies. Plant Biotechnol J. 2013;11(9):1029-33. doi:10.1111/pbi.12127.

24. Whaley KJ, Morton J, Hume S, Hiatt E, Bratcher B, Klimyuk V, et al. Emerging antibody-based products. Curr Top Microbiol Immunol. 2014;375:107-26. doi:10.1007/82_2012_240.

25. Fox JL. First plant-made biologic approved. Nat Biotechnol. 2012;30(6):472. doi:10.1038/nbt0612-472.

26. Cohrs RJ, Martin T, Ghahramani P, Bidaut L, Higgins PJ, Shahzad A. Translational medicine definition by the European Society for Translational Medicine. New Horiz Trans Med. 2015;2(3):86-8. doi:10.1016/j.nhtm.2014.12.002.

27. Howe KS, Hasler B, Stark KD. Economic principles for resource allocation decisions at national level to mitigate the effects of disease in farm animal populations. Epidemiol Infect. 2013;141(1): 91-101. doi:10.1017/S095026881200060X.

28. Garforth C. Livestock keepers' reasons for doing and not doing things which governments, vets and scientists would like them to do. Zoonoses Public Health. 2015;62 Suppl 1:29-38. doi:10.1111 /zph.12189.
29. Buyel JF. Process development strategies in plant molecular farming. Curr Pharm Biotechnol. 2015;16(11):966-82.

30. Peyret H, Lomonossoff GP. When plant virology met Agrobacterium: the rise of the deconstructed clones. Plant Biotechnol J. 2015;13(8):1121-35. doi:10.1111/pbi.12412.

31. Gleba YY, Tuse D, Giritch A. Plant viral vectors for delivery by Agrobacterium. Curr Top Microbiol Immunol. 2014;375:155-92. doi:10.1007/82_2013_352.

32. Waheed MT, Sameeullah M, Khan FA, Syed T, Ilahi M, Gottschamel J, et al. Need of cost-effective vaccines in developing countries: what plant biotechnology can offer? SpringerPlus. 2016;5:65. doi:10.1186/s40064-016-1713-8.

33. Bock KW. The UDP-glycosyltransferase (UGT) superfamily expressed in humans, insects and plants: animal-plant arms-race and co-evolution. Biochem Pharmacol. 2016;99:11-7. doi:10.1016/j.bcp.2015.10.001.

34. Abell BM, High S, Moloney MM. Membrane protein topology of oleosin is constrained by its long hydrophobic domain. J Biol Chem. 2002;277(10):8602-10. doi:10.1074/jbc.M103712200.

35. Joensuu JJ, Conley AJ, Lienemann M, Brandle JE, Linder MB, Menassa R. Hydrophobin fusions for high-level transient protein expression and purification in Nicotiana benthamiana. Plant Physiol. 2010;152(2):622-33. doi:10.1104/pp.109.149021.

36. Torrent M, Llop-Tous I, Ludevid MD. Protein body induction: a new tool to produce and recover recombinant proteins in plants. Methods Mol Biol. 2009;483:193-208. doi:10.1007/978-1-59745407-0_11.

37. Floss DM, Mockey M, Zanello G, Brosson D, Diogon M, Frutos R, et al. Expression and immunogenicity of the mycobacterial Ag85B/ ESAT-6 antigens produced in transgenic plants by elastin-like peptide fusion strategy. J Biomed Biotechnol. 2010;2010:274346. doi:10.1155/2010/274346.

38. Wade KL, Ito Y, Ramarathnam A, Holtzclaw WD, Fahey JW. Purification of active myrosinase from plants by aqueous twophase counter-current chromatography. Phytochem Anal. 2015;26(1):47-53. doi:10.1002/pca.2535.

39. Phan HT, Hause B, Hause G, Arcalis E, Stoger E, Maresch D, et al. Influence of elastin-like polypeptide and hydrophobin on recombinant hemagglutinin accumulations in transgenic tobacco plants. PLoS One. 2014;9(6):e99347. doi:10.1371/journal.pone.0099347.

40. Phan HT, Pohl J, Floss DM, Rabenstein F, Veits J, Le BT, et al. ELPylated haemagglutinins produced in tobacco plants induce potentially neutralizing antibodies against $\mathrm{H} 5 \mathrm{~N} 1$ viruses in mice. Plant Biotechnol J. 2013;11(5):582-93. doi:10.1111/pbi.12049.

41. Conley AJ, Joensuu JJ, Richman A, Menassa R. Protein bodyinducing fusions for high-level production and purification of recombinant proteins in plants. Plant Biotechnol J. 2011;9(4):419-33. doi:10.1111/j.1467-7652.2011.00596.x.

42. Hofbauer A, Melnik S, Tschofen M, Arcalis E, Phan HT, Gresch U, et al. The encapsulation of hemagglutinin in protein bodies achieves a stronger immune response in mice than the soluble antigen. Front Plant Sci. 2016;7:142. doi:10.3389/fpls.2016.00142.

43. Whitehead GS, Thomas SY, Cook DN. Modulation of distinct asthmatic phenotypes in mice by dose-dependent inhalation of microbial products. Environ Health Perspect. 2014;122(1):34-42. doi:10.1289/ehp.1307280.

44. Frandoloso R, Martinez-Martinez S, Calmettes C, Fegan J, Costa E, Curran D, et al. Nonbinding site-directed mutants of transferrin binding protein $\mathrm{B}$ exhibit enhanced immunogenicity and protective capabilities. Infect Immun. 2015;83(3):1030-8. doi:10.1128 /IAI.02572-14.

45. Pelosi A, Shepherd R, Walmsley AM. Delivery of plant-made vaccines and therapeutics. Biotechnol Adv. 2012;30(2):440-8. doi:10.1016/j.biotechadv.2011.07.018.

46. Shaaltiel Y, Gingis-Velitski S, Tzaban S, Fiks N, Tekoah Y, Aviezer D. Plant-based oral delivery of beta-glucocerebrosidase as an 
enzyme replacement therapy for Gaucher's disease. Plant Biotechnol J. 2015;13(8):1033-40. doi:10.1111/pbi.12366.

47. Rosales-Mendoza S, Salazar-Gonzalez JA. Immunological aspects of using plant cells as delivery vehicles for oral vaccines. Expert Rev Vaccines. 2014;13(6):737-49. doi:10.1586 /14760584.2014.913483.

48. Marsian J, Lomonossoff GP. Molecular pharming - VLPs made in plants. Curr Opin Biotechnol. 2016;37:201-6. doi:10.1016/j. copbio.2015.12.007.

49. Perez Aguirreburualde MS, Gomez MC, Ostachuk A, Wolman F, Albanesi G, Pecora A, et al. Efficacy of a BVDV subunit vaccine produced in alfalfa transgenic plants. Vet Immunol Immunopathol. 2013;151(3-4):315-24. doi:10.1016/j.vetimm.2012.12.004.

50. Rosales-Mendoza S, Soria-Guerra RE, Moreno-Fierros L, GoveaAlonso DO, Herrera-Diaz A, Korban SS, et al. Immunogenicity of nuclear-encoded LTB:ST fusion protein from Escherichia coli expressed in tobacco plants. Plant Cell Rep. 2011;30(6):1145-52. doi:10.1007/s00299-011-1023-0.

51. Clarke JL, Waheed MT, Lossl AG, Martinussen I, Daniell H. How can plant genetic engineering contribute to cost-effective fish vaccine development for promoting sustainable aquaculture? Plant Mol Biol. 2013;83(1-2):33-40. doi:10.1007/s11103-013-0081-9.

52. Alfano EF, Lentz EM, Bellido D, Dus Santos MJ, Goldbaum FA, Wigdorovitz A, et al. Expression of the multimeric and highly immunogenic Brucella spp. lumazine synthase fused to bovine rotavirus VP8d as a scaffold for antigen production in tobacco chloroplasts. Front Plant Sci. 2015;6:1170. doi:10.3389/fpls.2015.01170.

53. Bellido D, Craig PO, Mozgovoj MV, Gonzalez DD, Wigdorovitz A, Goldbaum FA, et al. Brucella spp. lumazine synthase as a bovine rotavirus antigen delivery system. Vaccine. 2009;27(1):136-45. doi:10.1016/j.vaccine.2008.10.018.

54. Mardanova ES, Kotlyarov RY, Kuprianov VV, Stepanova LA, Tsybalova LM, Lomonossoff GP, et al. High immunogenicity of plant-produced candidate influenza vaccine based on the M2e peptide fused to flagellin. Bioengineered. 2016;7(1):28-32. doi:10.1080/21655979.2015.1126017.

55. Potera C. Vaccine manufacturing gets boost from tobacco plants. Genet Eng Biotechnol News. 2012;32(6):8-10. doi:10.1089 /gen.32.6.02.

56. Chambers MA, Graham SP, La Ragione RM. Challenges in veterinary vaccine development and immunization. Methods Mol Biol. 2016;1404:3-35. doi:10.1007/978-1-4939-3389-1 1.

57. Phan HT, Floss DM, Conrad U. Veterinary vaccines from transgenic plants: highlights of two decades of research and a promising example. Curr Pharm Des. 2013;19(31):5601-11.

58. Horn ME, Woodard SL, Howard JA. Plant molecular farming: systems and products. Plant Cell Rep. 2004;22(10):711-20. doi:10.1007/s00299-004-0767-1.

59. Tuse D. Safety of plant-made pharmaceuticals: product development and regulatory considerations based on case studies of two autologous human cancer vaccines. Hum Vaccin. 2011;7(3):32230.

60. Macdonald P. Developing workable regulatory frameworks for the environmental release of transgenic plants. Collection Biosaf Rev. 2012;60:126-59.

61. Fujiuchi N, Matoba N, Matsuda R. Environment control to improve recombinant protein yields in plants based on agrobacteriummediated transient gene expression. Front Bioeng Biotechnol. 2016;4:23. doi:10.3389/fbioe.2016.00023.

62. FMI. Veterinary vaccines market: faster innovation and better relationship management key to garner higher market shares: future market insight. 2016.

63. Knight-Jones TJ, Bulut AN, Gubbins S, Stark KD, Pfeiffer DU, Sumption KJ, et al. Retrospective evaluation of foot-and-mouth disease vaccine effectiveness in Turkey. Vaccine. 2014;32(16): 1848-55. doi:10.1016/j.vaccine.2014.01.071.
64. Sylla D, Rweyemamu MM, Palya VJ. Regulatory framework and requirements for managing risks associated with veterinary biological products in Africa: present systems and future needs. Rev Sci Tech. 1995;14(4):1171-84.

65. Di Girolamo N, Meursinge Reynders R. Deficiencies of effectiveness of intervention studies in veterinary medicine: a cross-sectional survey of ten leading veterinary and medical journals. PeerJ. 2016;4:e1649. doi:10.7717/peerj.1649. This paper describes a unique model of a public and private international alliance, that works toward a common goal of manufacturing and supplying high-quality vaccines in developing countries.

66. Knight-Jones TJ, Edmond K, Gubbins S, Paton DJ. Veterinary and human vaccine evaluation methods. Proc Biol Sci / R Soc. 2014;281(1784):20132839. doi:10.1098/rspb.2013.2839.

67. O'Brien D, Zanker S. Animal vaccination and the veterinary pharmaceutical industry. Rev Sci Tech. 2007;26(2):471-7.

68. McLeod A, Rushton J. Economics of animal vaccination. Rev Sci Tech. 2007;26(2):313-26.

69. Weinberg GA, Szilagyi PG. Vaccine epidemiology: efficacy, effectiveness, and the translational research roadmap. J Infect Dis. 2010;201(11):1607-10. doi:10.1086/652404.

70. Sicuri E, Evans DB, Tediosi F. Can economic analysis contribute to disease elimination and eradication? A systematic review. PLoS One. 2015;10(6):e0130603. doi:10.1371/journal.pone.0130603.

71. Kremer M. Pharmaceuticals and the developing world. J Econ Perspect J Am Econ Assoc. 2002;16(4):67-90.

72. Roth JA. Veterinary vaccines and their importance to animal health and public health. Procedia Vaccinology. 2011;5:127-36. doi:10.1016/j.provac.2011.10.009.

73. Perry B, Grace D. The impacts of livestock diseases and their control on growth and development processes that are pro-poor. Philos Trans R Soc Lond B Biol Sci. 2009;364(1530):2643-55. doi:10.1098/rstb.2009.0097.

74. Richens IF, Hobson-West P, Brennan ML, Lowton R, Kaler J, Wapenaar W. Farmers' perception of the role of veterinary surgeons in vaccination strategies on British dairy farms. Vet Rec. 2015;177(18):465. doi:10.1136/vr.103415.

75. Kremer M. Creating markets for new vaccines - part I: rationale. In: Jaffe A, Lerner J, Stern S, editors. Innovation Policy and the Economy. MIT Press; 2001. p. 35-72.

76. Korenblit J. Biotechnology innovations in developing nations. Biotechnol Healthc. 2006;3(1):55-8.

77. Bregu M, Draper SJ, Hill AV, Greenwood BM. Accelerating vaccine development and deployment: report of a Royal Society satellite meeting. Philos Trans R Soc Lond B Biol Sci. 2011;366(1579): 2841-9. doi:10.1098/rstb.2011.0100.

78. Cordero C, Delino R, Jeyaseelan L, Lansang MA, Lozano JM, Kumar S, et al. Funding agencies in low- and middle-income countries: support for knowledge translation. Bull World Health Organ. 2008;86(7):524-34.

79. Abuduxike G, Aljunid SM. Development of health biotechnology in developing countries: can private-sector players be the prime movers? Biotechnol Adv. 2012;30(6):1589-601. doi:10.1016/j. biotechadv.2012.05.002.

80. Naude W, Szirmai A, Goedhuys M. Innovation and entrepreneurship in developing countries. 2011. Report No.: 1814-8026.

81. OECD. Innovation for development report. In: Development OfEC-oa, editor. 2012.

82. de Castro L. Brazilian biotechnology network - the challenge to innovate in biotechnology in Brazil. BMC Proc. 2014;8 Suppl 4: O40. doi:10.1186/1753-6561-8-s4-o40.

83. Barreto de Castro L, editor. Brazilian biotechnology network - the challenge to innovate in biotechnology in Brazil. 5th Congress of the Brazilian Biotechnology Society (SBBIOTEC); 2014; Florianopolis, Brazil: BMC. 
84. Castro LA, Barros AK. Incentives for Brazilian health biotech. Nat Biotechnol. 2009;27(4):317-8. doi:10.1038/nbt0409-317.

85. Pecora A, Malacari DA, Perez Aguirreburualde MS, Bellido D, Nunez MC, Dus Santos MJ, et al. Development of an APCtargeted multivalent E2-based vaccine against Bovine Viral Diarrhea Virus types 1 and 2. Vaccine. 2015;33(39):5163-71. doi:10.1016/j.vaccine.2015.07.106.

86. Nene V, editor. Planting the Orchard: ILVAC - An ILRI Livestock Vaccine Initiative. Tropentag. Bridging the gap between increasing knowledge and decreasing resources; 2014.

87. Shams H. Recent developments in veterinary vaccinology. Vet J. 2005;170(3):289-99. doi:10.1016/j.tvj1.2004.07.004.

88. Sparrow P, Broer I, Hood EE, Eversole K, Hartung F, Schiemann J. Risk assessment and regulation of molecular farming - a comparison between Europe and US. Curr Pharm Des. 2013;19(31):5513-30.
89. Rathore AS. Roadmap for implementation of quality by design $(\mathrm{QbD})$ for biotechnology products. Trends Biotechnol. 2009;27(9):546-53. doi:10.1016/j.tibtech.2009.06.006.

90. Ruiz V, Mozgovoj MV, Dus Santos MJ, Wigdorovitz A. Plantproduced viral bovine vaccines: what happened during the last 10 years? Plant Biotechnol J. 2015;13(8):1071-7. doi:10.1111/pbi.12440.

91. Pagliusi S, Makhoana M, Datla M, Leite L, Hendriks J, Gholami A, et al. Developing Countries Vaccine Manufacturers Network (DCVMN): engaging to step up for vaccine discovery and access. Meeting report 2012. Vaccine. 2013;31(31):3111-5. doi:10.1016/j. vaccine.2013.04.082.

92. Pagliusi S, Leite LC, Datla M, Makhoana M, Gao Y, Suhardono M, et al. Developing Countries Vaccine Manufacturers Network: doing good by making high-quality vaccines affordable for all. Vaccine. 2013;31 Suppl 2:B176-83. doi:10.1016/j.vaccine.2012.11.060. . 